\title{
CONTEXTUALIZANDO A TRANSPOSIÇÃO DO RIO SÃO FRANCISCO: CONSIDERAÇÕES SOBRE A INTEGRAÇÃO ENTRE O PROJETO E DEMANDAS DAS COMUNIDADES RURAIS
}

Everton Nogueira Silva ${ }^{1}$, Patrícia Verônica Pinheiro Sales Lima ${ }^{2}$, Francisco Casimiro Filho $^{3}$

1. Doutorando em Desenvolvimento e Meio Ambiente - PRODEMA, Departamento de Economia Agrícola, Campus do Pici, Bloco 826, Universidade Federal do Ceará, Fortaleza-CE, Brasil. (enogueirasilva@hotmail.com)

2. Profa do Programa de Pós-Graduação em Desenvolvimento e Meio Ambiente PRODEMA, Departamento de Economia Agrícola, Campus do Pici, Bloco 826, Universidade Federal do Ceará, Fortaleza-CE, Brasil.

3. Prof. Associado I, Departamento de Economia Agrícola, Campus do Pici, Bloco 826, Universidade Federal do Ceará, Fortaleza-CE, Brasil.

Recebido em: 08/04/2017 - Aprovado em: 10/06/2017 - Publicado em: 20/06/2017 DOI: 10.18677/EnciBio_2017A146

\begin{abstract}
RESUMO
O semiárido brasileiro é uma região amplamente habitada e historicamente exposta a problemas de escassez de água provocada por condições climáticas instáveis que acarretam em períodos recorrentes de seca. A oferta de recursos hídricos na região permeia decisões que envolvem mudanças nos âmbitos: social, econômicos e ambiental do desenvolvimento local. Após anos de ações centralizadas, definidas e implementadas por meio de processos topdown, nota-se uma crescente participação da população nos processos de tomada de decisão. Este artigo teve como objetivo discutir como o projeto de transposição do Rio São Francisco contextualiza as demandas das comunidades rurais (as principais afetadas pela obra de transposição) no que diz respeito à estrutura agrária, e gestão das águas. Neste cenário, percebe-se a importância de integração de gestores e população na criação de redes unidas pelo interesse não só de uma melhor gestão dos recursos hídricos, como também voltadas para o desenvolvimento sustentável da região através da aplicação de ações promotoras para a boa governança.
\end{abstract}

PALAVRAS-CHAVE: Gestão, Políticas Públicas, Transposição.

\section{CONTEXTING THE TRANSPOSITION OF THE SÃO FRANCISCO RIVER: CONSIDERATIONS ABOUT AN INTEGRATION BETWEEN THE PROJECT AND THE DEMANDS OF RURAL COMMUNITIES}

\footnotetext{
ABSTRACT

The Brazilian semi-arid region is a largely inhabited region and historically exposed to problems of water shortage caused by unstable climatic conditions that lead to recurrent periods of drought. The supply of water resources in the region permeates decisions that involve changes in the social, economic and environmental spheres of local development. After years of centralized actions, defined and implemented ENCICLOPÉDIA BIOSFERA, Centro Científico Conhecer - Goiânia, v.14 n.25; p.1772 2017
} 
through topdown processes, there is a growing participation of the population in the decision-making processes. This article aims to discuss how the São Francisco River transposition project contextualizes the demands of rural communities (the main ones affected by the work of transposition) in terms of agrarian structure, and water management. In this scenario, the importance of integration of managers and population in the creation of networks united by the interest not only in a better management of water resources, but also in the sustainable development of the region through the application of actions promoting good governance .

KEYWORDS: Management, Public Policy, Transposition.

\section{INTRODUÇÃO}

Como recurso ambiental, a água doce fundamenta-se como mola mestre sobre a perspectiva da mudança social. Uma das questões polemizadas no debate sobre o tema da transposição do rio São Francisco diz respeito ao uso da água como um recurso ambiental escasso e limitado, cuja distribuição deve obedecer a preceitos sustentáveis para evitar conflitos sociais e um grande desgaste ambiental (NETO \& VIANNA, 2016). Essa questão é fundamental para a efetividade da transposição, porém apresenta lacunas de conhecimento que ameaçam a incorporação dos fundamentos da "Racionalidade Ambiental" definida por LEFF (2010) citado por DERANI \& JODAS (2015) como a incorporação dos valores ambientais e sociais na lógica de produção tendo por objetivo aplicar tecnologias que minimizem os impactos ambientais e que coloque o controle social do processo produtivo ao interesse do conjunto da sociedade. Já DOMINGUES (2015) observa que a transposição do rio São Francisco assume uma dimensão regional devido ao seu potencial de uso múltiplo para geração de energia elétrica, pesca, irrigação e ordenamento territorial.

Trata-se assim, de uma temática inserida na gestão das águas para o semiárido, a qual deve ser pautada por políticas públicas permanentes e apropriadas para diferentes realidades sociais, ampliando a capacidade humana local e quebrando com as estruturas de concentração da terra, da água, do poder e do acesso a serviços sociais básicos. Nessa perspectiva, torna-se relevante discutir as mudanças provocadas pela transposição nas áreas rurais, com ênfase na estrutura agrária e gestão da água na região Nordeste.

Considerando a prevalência de estudos técnicos sobre o tema transposição, este artigo teve como objetivo analisar como o projeto de transposição do Rio São Francisco contextualiza as demandas das comunidades rurais (as principais afetadas pela obra de transposição) no que diz respeito à estrutura agrária, e gestão das águas.

\section{A SUSTENTABILIDADE SOCIOAMBIENTAL DA TRANSPOSIÇÃO DE RIOS: UM ESPAÇO DE DISCUSSÃO}

\section{As transposições de rios no mundo}

Partindo para uma abertura sobre a temática transposição de rios, MELLO (2006), abre espaço de discussão sobre a real necessidade da ação transposição de rios sob o aspecto socioambiental, no qual há um vultoso emprego de recursos econômicos aplicados em condições socialmente injustas e ambientalmente drásticas. Já HENKES (2014, p.498) sobre o tema transposição do rio São Francisco observa que: 


\begin{abstract}
Não obstante, os impactos, danos e riscos ambientais (sociedade e natureza) foram minimizados ou desconsiderados pelo Governo Federal (Presidência da República, Secretarias, Ibama, ANA, MIN etc.) e, em especial, no Relatório de Impacto ao Meio Ambiente (RIMA). Muitos estudos e, inclusive, o RIMA atestam que a obra ocasionará a perda e a extinção de espécies da flora e fauna, interferências em espaços protegidos, aumento e/ou aparecimento de doenças, acidentes com a população, ruptura de relações sociocomunitárias, introdução de riscos e tensões sociais, portanto, acenando para a sua insustentabilidade etc.
\end{abstract}

Alguns aspectos também são discutidos com o aumento na quantidade demandada de água para irrigação pós transposição do rio São Francisco: o primeiro relaciona-se com a redução da segurança alimentar levando os agricultores mais pobres do semiárido do nordeste a uma situação maior de vulnerabilidade com relação ao acesso aos gêneros alimentícios e o segundo refere-se as mudanças também ocorrentes no escoamento das bacias hidrográficas do semiárido que poderão acarretar prejuízos ao potencial de geração hidrelétrica do país (PBMC, 2012; SILVEIRA et al., 2014).

BISWAS (1970) destaca que para a transposição de rios é necessário verificar alguns sistemas relevantes para que haja a sustentabilidade socioambiental na integralização de bacias hídricas, tais como: I - Sistema Físico: a) Quantidade de Água - nível; descarga; velocidade; águas subterrâneas; perdas. b) Qualidade de Água - sedimentos; nutrientes; turbidez; salinidade e alcalinidade; temperatura; substâncias químicas tóxicas. c) Implicações sobre os solos - erosão; sedimentação; salinidade; alcalinidade; mudanças em padrões de uso de terra; mudanças da caracterização mineral e conteúdo de nutrientes no solo; indução a terremotos; outros fatores relativos à hidrogeologia. d) Atmosfera - temperatura; evapotranspiração; mudanças microclimáticas; mudanças macroclimáticas. II Sistema Biológico: a) Ambiente aquático - phytoplancton; peixes e vertebrados aquáticos; plantas; vetores de doença. b) Biodiversidade em geral - animais; vegetação; perda de hábitat; encarecimento de hábitat. III - Sistema Humano: a) Produção - agricultura; aquicultura; geração de energia; transporte (navegação); indústrias; recreação; mineração. b) Sociocultural - custos sociais, inclusive reassentamento das pessoas; desenvolvimento de infraestrutura complementar; efeitos antropológicos; implicações políticas. Os exemplos de experiências mal sucedidas de transposição de rios são frequentes (Quadro 1). 
QUADRO 1 - Experiências internacionais de transposição de rios .

\begin{tabular}{|c|c|c|c|c|}
\hline Continente & Obra & Características & Principais Impactos & Referências \\
\hline Ásia & $\begin{array}{l}\text { Canais de } \\
\text { desvio das } \\
\text { águas dos } \\
\text { rios Amu } \\
\text { Darya e o } \\
\text { Syr Darya }\end{array}$ & $\begin{array}{l}\text { Construídos na década de } 1940 \\
\text { na Rússia para a produção de } \\
\text { algodão na região do } \\
\text { Uzbequistão. }\end{array}$ & $\begin{array}{l}\text { Seca e salinização excessiva ao Mar de Aral. } \\
\text { As perdas de água, seu uso e a vazão afluente } \\
\text { para o Mar de Aral, no ano de } 1960 \text {, foram de } 13 \\
\text { bilhões de } \mathrm{m}^{3}, 48 \text { bilhões de } \mathrm{m}^{3} \text { e } 54 \text { bilhões de } \mathrm{m}^{3} \text {, } \\
\text { respectivamente, enquanto que para o ano de } 1990 \\
\text { esses valores foram de } 7 \text { bilhões de } \mathrm{m}^{3}, 103 \\
\text { bilhões de } \mathrm{m}^{3} \text { e } 5 \text { bilhões de } \mathrm{m}^{3} \text {, respectivamente. }\end{array}$ & LIMA (2010) \\
\hline Europa & $\begin{array}{l}\text { Transposição } \\
\text { Tajo-Segura }\end{array}$ & $\begin{array}{l}\text { A ideia da transposição surgiu } \\
\text { em } 1933 \text { e foi retomada na } \\
\text { ditadura de Francisco Franco, } \\
\text { sendo a obra concluída em } 1973 \text {. } \\
\text { A vazão média transposta é de } \\
33 \mathrm{~m}^{3} / \mathrm{s} \text { em uma extensão de } \\
242 \mathrm{~km} \text {. } \\
\text { O aqueduto Tajo-Segura } \\
\text { transpõe água do Rio Tajo } \\
\text { (região centro sul) para o Rio } \\
\text { Segura (região de Múrcia) ao sul } \\
\text { da Espanha. }\end{array}$ & $\begin{array}{l}\text { Destruição de milhares de hectares de vegetação } \\
\text { nativa, degradação da qualidade da água do rio } \\
\text { Tajo proveniente do lançamento de efluentes da } \\
\text { cidade de Madri; alteração da vegetação ribeirinha } \\
\text { dada a carga de poluentes; crescimento } \\
\text { exponencial da demanda de água, uso intensivo de } \\
\text { agroquímicos e desenvolvimento insustentável nos } \\
\text { setores de turismo e agricultura na região da } \\
\text { transposição dada a redução da vazão ecológica. }\end{array}$ & CAÚLA (2006) \\
\hline América & $\begin{array}{l}\text { Transposição } \\
\text { do Rio } \\
\text { Colorado nos } \\
\text { Estados } \\
\text { Unidos }\end{array}$ & $\begin{array}{l}\text { Passa por sete estados - } \\
\text { Wyoming, Colorado, Utah e } \\
\text { Novo México, Nevada, Arizona e } \\
\text { Califórnia, percorrendo cerca de } \\
2300 \mathrm{~km} \text {, chegando a fronteira } \\
\text { do México apresentando uma } \\
\text { extensão de } 450 \mathrm{~km} \text { e drenando } \\
\text { uma área de } 5.500 \mathrm{~km}^{2} \text { nessa } \\
\text { porção. }\end{array}$ & $\begin{array}{l}\text { Oportunidades econômicas e sociais com a } \\
\text { fruticultura irrigada, mas com consequências } \\
\text { ambientais: desertificação, salinização das águas } \\
\text { do Baixo Colorado e a quase extinção de várias } \\
\text { espécies de peixes. } \\
\text { Aumento de grandes inundações, ocorrentes na } \\
\text { parte inferior do Rio Colorado, que afetaram o } \\
\text { sistema dos canais que fornecem habitat para a } \\
\text { biodiversidade aquática e ribeirinha. }\end{array}$ & LIMA (2010), \\
\hline África & $\begin{array}{ll}\text { Canal } & \text { El- } \\
\text { Salam } & \text { no } \\
\text { Egito } & \end{array}$ & $\begin{array}{l}\text { A água do canal El-Salam é } \\
\text { captada no braço do Damietta } \\
\text { Rio Nilo e misturada com a água }\end{array}$ & $\begin{array}{l}\text { A transposição buscou a integração das cadeias } \\
\text { produtivas da agricultura, agroindústria, mineração, } \\
\text { produção de energia, turismo e outras atividades }\end{array}$ & $\begin{array}{l}\text { QUOSY } \\
\text { (2005) }\end{array}$ \\
\hline
\end{tabular}




\begin{tabular}{|c|c|c|c|c|}
\hline & & $\begin{array}{l}\text { de drenagem dos canais Serw e } \\
\text { Hadous, na razão } 1: 1, \text { de } \\
\text { maneira que a salinidade não } \\
\text { ultrapasse o limite crítico } \\
\text { aceitável pelas espécies } \\
\text { agricultáveis. }\end{array}$ & $\begin{array}{l}\text { urbanas e industriais; criação de novos postos de } \\
\text { emprego para os jovens da região e redistribuição } \\
\text { da população para as áreas desabitadas do } \\
\text { deserto do Sinai - } 25 \% \text { até o ano de } 2017 \text {. Mas } \\
\text { estudos apontam: perda de habitats naturais; } \\
\text { perdas de sítios arqueológicos; deslocamento da } \\
\text { população de beduínos do Sinai e ruptura de } \\
\text { costumes sociais e de uso da terra; aumento do } \\
\text { risco à saúde de pessoas e à vida de animais } \\
\text { silvestres; e e) problemas de usos competitivos } \\
\text { com os outros usuários de água do delta do Nilo, } \\
\text { do qual a água está sendo retirada. }\end{array}$ & \\
\hline Oceania & $\begin{array}{l}\text { Snowy } \\
\text { Mountains } \\
\text { Hydroelectric } \\
\text { Scheme } \\
\text { (SMHS), na } \\
\text { Austrália }\end{array}$ & $\begin{array}{l}\text { O SMHS foi construído entre } \\
1949 \text { e } 1974 \text {. } \\
\text { É constituído por } 16 \text { reservatório, } \\
7 \text { usinas, } 1 \text { estação de } \\
\text { bombeamento, } 145 \mathrm{~km} \text { de túneis } \\
\text { e } 80 \mathrm{~km} \text { de adutoras, sendo } \\
\text { desviado o percurso natural do } \\
\text { Rio Snowy para os rios Murray e } \\
\text { Murrumbidgee. }\end{array}$ & $\begin{array}{l}\text { Houve alterações no habitat com a abundância de } \\
\text { espécies (árvores exóticas); aumento na extensão } \\
\text { da intrusão salina impactando a produção agrícola } \\
\text { em áreas de várzea; erosão das margens nas } \\
\text { bacias dos rios Murray e Murrumbidgee devido ao } \\
\text { acréscimo da vazão d) aumento na quantidade } \\
\text { lançada de efluentes urbanos, industriais e } \\
\text { agrícolas. }\end{array}$ & SHRE (2004), \\
\hline
\end{tabular}


A preocupação com a gestão de obras de transposição encontra-se bem retratada, ainda, na transposição do Rio Colorado. AZEVEDO et al. (2005) destacam a legislação discutida e posteriormente implementada para o uso de diferentes vazões denominada de Tratado do Rio Colorado (1902), pois se temia que somente o estado da Califórnia seria o maior beneficiário com a construção de barragens de regularização e controle das cheias. O principal objetivo do tratado foi o de reservar as quantidades mínimas de água que cada estado poderia utilizar de forma consultiva.

As discussões se arrastaram por décadas e somente em 1923 o tratado foi implementado, porém sem a adesão do estado do Arizona. O Estado do Arizona aderiu ao tratado em 1944. Foram definidas pela Suprema Corte Americana as seguintes cotas para cada estado: a) Califórnia: $172,1 \mathrm{~m}^{3} / \mathrm{s}$; b) Arizona: $109,5 \mathrm{~m}^{3} / \mathrm{s}$; c) Nevada: $11,7 \mathrm{~m}^{3} / \mathrm{s}$; d) Colorado: $151,8 \mathrm{~m}^{3} / \mathrm{s}$; e) Utah: $67,5 \mathrm{~m}^{3} / \mathrm{s}$; f) Wyoming: 41,1 $\mathrm{m}^{3} / \mathrm{s}$ e g) Novo México: $33,0 \mathrm{~m}^{3} / \mathrm{s}$. O Tratado do rio Colorado é um exemplo notável da complexidade que a gestão de águas pode vir a apresentar por se tratar de um recurso escasso não tendo desde a sua implantação uma existência tranquila sob aspectos de regulamentação, havendo inúmeras intervenções da Suprema Corte Americana nas questões pertinentes (AZEVEDO et al. 2005).

A organização World Wide Found for Nature - WWF, no relatório intitulado "Pipedreams? Interbasin water transfers and water shortages", observa que um dos fatores chave que mina os esforços para a questão da sustentabilidade socioambiental da transposição de rios refere-se ao fato de que as organizações públicas não buscam um espaço de diálogo entre si, havendo um movimento de segregação e não de integração da sociedade (WWF, 2007). Abre-se assim um espaço para o debate sobre a necessidade de ampliar a gestão participativa da sociedade com relação ao uso do recurso ambiental água diante de projetos de transposição de rios, pois cada vez mais se torna desnecessário pensar em projetos de transposição de rios que não façam uma reflexão em suas propostas sobre os aspectos e/ou impactos sociais, econômicos e ambientais, enfim, não se concebe a elaboração de projetos de transposição que não atendam as demandas das populações impactadas.

\section{O caso Brasil: a transposição do rio São Francisco}

A experiência internacional reforça o quanto a transposição de rios é discutível sob os três pilares fundamentais do desenvolvimento: o econômico, o social e o ambiental, não sendo diferente para a transposição do rio São Francisco que busca "atenuar" os efeitos da sazonalidade de chuvas - períodos de seca - para a região semiárida brasileira (DOMINGUES, 2015).

GOMES (2001) destaca que "nos três últimos séculos, registros acerca dos eventos climáticos ocorridos na região se tornaram mais confiáveis. Nesse período, por 85 anos as chuvas foram escassas, inexistentes ou mal distribuídas no semiárido nordestino". Sobre o modo de produção e reprodução da população camponesa nordestina, CASTRO $(2011$, p. 8) destaca que: "à escassez ou à má distribuição das chuvas soma-se o fato de que aproximadamente 10 milhões de habitantes do Semiárido obtêm o sustento da agricultura e da pecuária tradicionais, atividades muito vulneráveis às secas".

Sob o aspecto social da seca, ALBUQUERQUE JÚNIOR (1999) evidencia que a partir da ocorrência do elevado grau de mortandade e de problemas sociais 
ocorridos no final do século XIX - seca de 1877-79 - a região Nordeste passou a ser classificada como a "terra das secas", abrindo um espaço para argumentos políticos quase irrefutáveis da necessidade eminente de obras e outras benesses para socorrer os flagelados, porém conforme observado ao longo da história, as ações sociais e obras públicas aos flagelados foram monopolizadas pelas elites dominantes locais. Já SILVA (2003, p.2) denuncia que:

[...] a seca foi feita vilã do drama nordestino, acobertando as formas dominantes da exploração econômica que criaram e reproduziram a concentração das riquezas e do poder político, gerando miséria e dependência de milhares de sertanejos. A concentração fundiária e a exploração da mão de obra dos sertanejos têm destaque na explicação da manutenção da miséria na região semiárida.

Foi nesse cenário de fragilidade que o plano de transposição do São Francisco seguiu a trajetória de discussões político-ideológico desde as primeiras ideias para sua concepção, no segundo reinado no século XIX, chegando à sociedade civil do século XXI. Sob as ações governamentais para a condução de obras públicas de combate à seca para o final do século XIX e início do século XX, MEDEIROS et al. (2011) destacam: a) construção do açude Cedro em Quixadá-CE; b) em 1909 é criado a Inspetoria de Obras Contra a Seca (IOCS) (atualmente Departamento Nacional de Obras Contra as Secas - DNOCS) e c) maior base técnica de ações contra as secas. Sob o aspecto da base técnica de ações contra a seca para o período, havia dois caminhos a serem discutidos, o primeiro seria o programa de açudagem e o outro seria a transposição do Rio São Francisco. A base técnica defendida pelo IOCS foi à açudagem.

NETO \& VIANNA (2016) defendem que, ao longo do século XX, a açudagem mostrou-se como a decisão mais acertada, pois chegou-se ao delineamento da formação da infraestrutura hidráulica atual da região Nordeste. Como forma de atenuar o agravamento da escassez hídrica - dadas as falhas na gestão de acesso à água da plataforma hídrica da açudagem - tem ocorrido discussões desde meados da década de 1990 a retomada do plano de ação transposição do rio São Francisco como um projeto de articulação político-social-econômico, que até então permaneceu "engavetado" nas pastas de ações para a solução do problema da seca para o Nordeste. Sobre alguns aspectos relacionados com as decisões políticas da transposição do rio São Francisco ocorridas nos últimos anos CASTRO (2011, p.11) evidencia:

\footnotetext{
A partir de 1995, no decorrer dos dois mandatos presidenciais de Fernando Henrique Cardoso, novas versões do projeto foram apresentadas, entre elas uma da equipe da Secretaria Especial de Políticas Regionais, uma do Ministério da Integração Nacional (MI) e outra da Companhia de Desenvolvimento do Vale do São Francisco (CODEVASF). Por motivos diferentes, nenhum desses projetos foi levado adiante. Chega-se então à fase atual de debates sobre a ideia de transposição de parte das águas do rio São Francisco como solução para amenizar os efeitos da seca em parte do Semiárido nordestino. Logo no primeiro mandato do presidente Luís Inácio Lula da Silva, entre 2003 e 2006, a ideia da transposição ressurgiu quando o presidente Lula incumbiu o então ministro da Integração Nacional, Ciro Gomes, de executar a obra.
} 
Segundo o Relatório de Impacto Ambiental apresentado pelo Ministério da Integração Nacional, a Transposição do Rio São Francisco justifica-se através de três motivos principais. O primeiro é que a região Nordeste, que possui apenas $3 \%$ da disponibilidade de água do país e abriga $28 \%$ da população brasileira, apresenta internamente uma grande irregularidade na distribuição dos seus recursos hídricos, uma vez que o rio São Francisco representa $70 \%$ de toda a oferta regional. O segundo é que há discrepância nas densidades demográficas no Semiárido nordestino (cerca de 10 hab/ $\mathrm{km}^{2}$ na maior parte da bacia do rio São Francisco e aproximadamente $50 \mathrm{hab} / \mathrm{km}^{2}$ no Nordeste Setentrional) fazendo com que, do ponto de vista da oferta hídrica, o semiárido brasileiro seja dividido em dois: o Semiárido da bacia do São Francisco, com 2 mil a $10 \mathrm{mil} \mathrm{m}^{3} / \mathrm{hab} / \mathrm{ano}$ de água disponível em rio permanente, e o semiárido do Nordeste Setentrional. O projeto de transposição prevê a captação de $1,4 \%\left(26 \mathrm{~m}^{3} / \mathrm{s}\right)$ do volume de água que o rio despeja no mar. Essa água será preciosa para o abastecimento das bacias dos rios Jaguaribe, no Ceará; Apodi, no Rio Grande do Norte; Piranhas-Açu, na Paraíba e no Rio Grande do Norte; Paraíba, na Paraíba; e Moxotó e Brígida, em Pernambuco. O terceiro é que a transposição do rio São Francisco tornar-se-á uma alternativa de investimento social viável para a redução da pobreza extrema no âmbito rural, pois sem água algumas localidades da região Nordeste estarão sempre fadadas ao subdesenvolvimento sem grandes perspectivas de mudanças sociais e/ou econômicas (BRASIL, 2004).

Em comparação a experiência mundial sob o aspecto transposição de rios nota-se que no caso da transposição brasileira há um espaço de diálogo político entre os "estados doadores" e os "estados receptores". No âmbito dos "estados doadores" há a premissa de se investir na revitalização para que o projeto como um todo possa ser aceitável ou até mesmo ativamente desejável (MELLO, 2008). Porém, CASTRO (2011, p.44) destaca que:

\footnotetext{
Mesmo considerando que a revitalização seja uma compensação válida para os estados doadores, ainda assim existem críticas. Entre estas, argumenta-se que os recursos destinados à revitalização são inferiores aos destinados à transposição e, possivelmente, não são suficientes para se recuperar a bacia do rio São Francisco.
}

Na tabela 1 verifica-se sob o aspecto da revitalização do rio São Francisco apenas uma ação com gastos expressivos entre 2008 e 2009: o sistema de implementação, ampliação ou melhoria dos sistemas públicos de esgotamento sanitário em municípios das bacias dos rios São Francisco e Parnaíba. SILVA (2014) destaca que há uma junção sistemática de agressões ao rio, tais como: contaminação das águas através da dispersão de pesticidas, agrotóxicos e fertilizantes devido ao uso intensivo da água aplicada na agricultura irrigada e problemas com erosão causados pela criação extensiva de gado, desmatamento e substituição da vegetação da margem, ocorrendo assoreamento intenso em alguns trechos onde não é mais possível a navegação. 
TABELA 1 - Gastos diretos do governo federal com a transposição do rio São Francisco e com ações relacionadas ao projeto de revitalização da bacia do rio São Francisco $(\mathrm{R} \$)$

\begin{tabular}{|c|c|c|c|c|c|}
\hline $\begin{array}{c}\text { Ação } \\
\text { Governamental }\end{array}$ & 2005 & 2006 & 2007 & 2008 & 2009 \\
\hline $\begin{array}{c}\text { Integração do rio } \\
\text { São Francisco } \\
\text { com as bacias do } \\
\text { nordeste } \\
\text { setentrional } \\
\end{array}$ & $50.552 .027,22$ & 17.293.281,22 & $20.978 .100,80$ & $160.339 .781,37$ & $311.433 .819,86$ \\
\hline Revitalização & $x$ & $\mathbf{x}$ & $\mathbf{x}$ & $x$ & $x$ \\
\hline $\begin{array}{c}\text { Recuperação e } \\
\text { preservação da } \\
\text { bacia do São } \\
\text { Francisco }\end{array}$ & $145.956,06$ & $859.493,27$ & $1.059 .008,18$ & $1.031 .566,57$ & $207.232,66$ \\
\hline $\begin{array}{c}\text { Melhoria da } \\
\text { Hidrovia do São } \\
\text { Francisco }\end{array}$ & - & - & $6.667,60$ & $8.122 .147,72$ & $2.224 .706,80$ \\
\hline $\begin{array}{c}\text { Obras de } \\
\text { revitalização e } \\
\text { recuperação do } \\
\text { rio São Francisco }\end{array}$ & $6.148 .119,53$ & $5.649 .464,91$ & $2.236 .522,07$ & $537.974,40$ & - \\
\hline $\begin{array}{c}\text { Recuperação e } \\
\text { controle de } \\
\text { processos } \\
\text { erosivos em } \\
\text { municípios das } \\
\text { bacias do São } \\
\text { Francisco e } \\
\text { Parnaíba }\end{array}$ & $1.173 .554,19$ & $5.475 .418,62$ & $1.255 .723,23$ & $3.029 .469,00$ & $2.577 .293,00$ \\
\hline $\begin{array}{c}\text { Implantação, } \\
\text { ampliação ou } \\
\text { melhoria dos } \\
\text { sistemas públicos } \\
\text { de esgotamento } \\
\text { sanitário em } \\
\text { municípios das } \\
\text { bacias do São } \\
\text { Francisco e } \\
\text { Parnaíba } \\
\end{array}$ & - & - & $6.488,64$ & $115.552 .314,38$ & $106.327 .864,84$ \\
\hline
\end{tabular}

Fonte: Portal da Transparência da Controladoria Geral da União. Adaptado de CASTRO (2011)

Nos estados receptores grandes volumes de investimentos públicos estão sendo aplicados para que se possa interligar a transposição às infraestruturas já existentes, tendo como exemplo o Eixão das Águas para o estado do Ceará. O Eixão das Águas é uma obra do governo federal com extensão de $225 \mathrm{~km}$ e realiza a transposição das águas do açude Castanhão, interligando as bacias hidrográficas do Jaguaribe à Região Metropolitana de Fortaleza. Além disso, reforça o abastecimento do complexo portuário e industrial do Pecém - CIPP (CORDEIRO, 2010). Nota-se que há toda uma dinâmica de recursos de capital para a execução da obra em si e pouco é realizado sob o aspecto da preservação e conservação da 
bacia do rio São Francisco, sendo poucas as ações de políticas e investimentos públicos que contemplem a emergência da conservação dos recursos ambientais do rio, desta forma a transposição do rio São Francisco assemelha-se aos problemas atuais e ou futuros apresentados neste manuscrito com relação à transposição de rios no mundo (DOMINGUES, 2015).

\section{A GESTÃO DAS ÁGUAS NO SEMIÁRIDO E GOVERNANÇA}

A região semiárida brasileira apresenta uma grande diversidade cultural e natural sendo comumente conhecida como uma região que apresenta longos períodos de seca. Porém apesar do fenômeno das secas, o semiárido brasileiro é um dos mais chuvosos do planeta com chuvas concentradas de forma espacial e temporal - quadra invernosa de fevereiro a junho - com médias entre 260 e $800 \mathrm{~mm}$, com déficits entre os níveis de precipitação e de evapotranspiração se configurando como uma condição climática adversa principalmente para os moradores das zonas rurais mais dispersas (ASSAD et al., 2016).

A principal alternativa pensada desde o final do século XIX para o semiárido nordestino, no sentido de atenuar os efeitos da seca, vem a ser a construção de açudes para armazenamento das águas da quadra "invernosa". De acordo com OLIVEIRA et al. (2017), desde que a seca é por definição um problema relacionado à falta de água, a solução encontrada é a acumulação de água em grandes quantidades estando os açudes espalhados por um vasto território no sertão do Nordeste. Em oposição a esse ideal chama atenção o fato, de que a grande maioria dos açudes construídos ao longo do século XX são subutilizados apresentando problemas de salinização devido a evaporação intensa tornando a própria água impropria para o consumo humano e para a agricultura (DOMINGUES, 2015).

Algumas ações promotoras de gestão dos recursos hídricos merecem destaque como o "Canal da Integração" para o estado do Ceará coordenado pela Companhia de Gestão dos Recursos Hídricos (COGERH) que conduz a água do reservatório do Castanhão por $225 \mathrm{~km}$ até a região metropolitana de Fortaleza. Outro exemplo são os 500 quilômetros de adutoras construídas no estado do Rio Grande do Norte. Estes dois exemplos expressam ações técnicas eficientes de aproveitamento das reservas hídricas (CIRILO, 2008).

Destaca-se no último parágrafo, o termo "ações técnicas eficientes", mas sob o aspecto social - redução da pobreza - não se sabe se são realmente eficientes. A construção e gestão dos açudes, ao longo do tempo, têm obedecido a lógica da injustiça ambiental apresentada por FERNANDES (2014) que configura-se como sendo uma distribuição desigual dos benefícios e dos impactos negativos das políticas ambientais entre os diferentes grupos da sociedade, ou seja, quando um determinado grupo não tem acesso pleno e igual a um dado recurso ambiental como por exemplo a água e acaba por arcar com as consequências dos impactos negativos relacionados ao mal uso ou ausência de gestão responsável.

Dando sequência a esse entendimento CHAMUSCA (2013) ressalta a discussão sobre a necessidade da construção de novos painéis de organização política, econômica e social que na sociedade contemporânea torna-se emergente na busca por repensar novos modelos de estratégias de governação dos territórios onde o Estado deixa de ser o único ator exclusivo na gestão territorial. Para TORRES (2016) a crise administrativa surgiu a partir da crescente incapacidade do Estado de administrar a esfera social que mais fortemente afeta, positiva e negativamente, as demandas por inclusão e integração social, ou seja, a 
incapacidade da governabilidade plena muitas vezes está associada à dependência do próprio Estado em formar alianças com os seus cidadãos - capacidade de articulação em partidos, associações e demais instituições administrativas - que se não forem bem tecidas não há viabilidade para atender os projetos de demandas sociais, ou seja, são os próprios agentes públicos ou servidores do Estado que possibilitam a viabilidade de implementação correta das políticas públicas.

É necessário abrir espaço para um debate no qual seja possível questionar as considerações de relação mercantil de utilização dos recursos hídricos, buscando o debate advogar sobre modelos de gestão que sejam mais igualitários e sustentáveis de acesso a água (FRACALANZA et al., 2013). HOLZMANN (2014) reconhece o papel dos atores não estatais nos processos decisórios dado o processo de cooperação descentralizada como instrumento para o desenvolvimento na esfera ambiental. Sobre o aspecto das decisões governamentais de mitigação dos efeitos da seca para o território semiárido brasileiro, MANCAL et al. (2016, p.2) destaca que:

\begin{abstract}
As ações governamentais para mitigação dos impactos da seca no semiárido brasileiro privilegiaram, por muitos anos, aspectos emergenciais e assistencialistas, sem um planejamento estratégico. No entanto, é inconteste a existência de um cenário de mudanças na governança da seca. Mais recentemente, a postura de combate à seca vem sendo substituída por estratégias de convivência. A população está sendo inserida, lentamente, em processos decisórios e adquirindo um papel de protagonismo, o qual é determinante para transformações efetivas, especialmente aquelas relacionadas à criação de capacidade adaptativa.
\end{abstract}

O conceito de governança e seus princípios - voz e responsabilização, estabilidade política, eficácia governamental, qualidade regulatória, estado de direito e controle da corrupção - recaem sobre a necessidade da construção de painéis que ampliem as discussões sociais entre os diferentes interlocutores sob quais benefícios sociais e/ou econômicos irão entrar em pauta e para quem (TORRES, 2016). Sobre a necessidade da governança como instrumental promotor da sustentabilidade ambiental, JACKSON (2013) defende que seus preceitos devem seguir uma lógica de organização de mecanismos de comprometimento que busquem satisfazer aos anseios de bem estar da sociedade não só a curto-prazo e sim a longo prazo, ou seja, se não houver uma organização, o homem da geração atual está fadado a escolher gastar todos os recursos agora. Assim, a governança assume a responsabilidade de equilibrar as decisões do governo com os anseios da sociedade na busca pelo uso racional dos recursos ecológicos hoje para que sejam garantidas reservas às gerações futuras (JACOBI \& SINISGALLI, 2012).

Dentre as ações de governança para a água, evidencia-se o papel dos comitês de bacias em todo Brasil como uma alternativa de incluir a participação de novos atores sociais na gestão das águas, principalmente no nordeste semiárido brasileiro. O objetivo principal dos comitês de bacias é o de promover novos arranjos institucionais dentro do próprio Estado de tal modo que os órgãos do governo possam a vir trabalhar de forma colaborativa incluindo ao mesmo tempo representantes do setor privado e de organizações da sociedade civil em assembleias, apresentando-se como entidades civis com funções consultivas e deliberativas, formadas pela sociedade civil organizada, usuários da água e pelos poderes públicos municipais, estaduais e federais (ABERS \& KECK, 2013).

Nota-se que a discussão relacionada à transposição do Rio São Francisco 
apresenta uma relação pouco específica sobre aspectos da construção de uma gestão que agregue um envolvimento mais social. Para que haja um planejamento focado na gestão de águas com bases sustentáveis se faz necessário elaborar e implementar planos de ação para os recursos hídricos, sendo que cada bacia hidrográfica deverá ter o seu plano de ação, pois sem uma gestão eficiente e participativa existe o risco de empresas, membros da comunidade, do próprio governo e de ONGs comprometerem potencialmente o equilíbrio ecossistêmico, gerando como consequências poluições em mananciais, açudes e rios (BARBOSA \& BARBOSA, 2013).

\section{CONSIDERAÇÕES FINAIS}

A transposição do Rio São Francisco não pode ser um retrocesso aos avanços conquistados na gestão integrada dos recursos hídricos e gestão das bacias hidrográficas no Nordeste brasileiro. Espera-se que a transposição contemple questões históricas como: quem toma as decisões sobre o uso da água? Quem serão os beneficiários e de que forma terão acesso ao recurso? Quais as bases científicas e políticas para a tomada de decisão? A resposta correta a essas questões requer a implementação de um sistema de governança da água que esteja aliado a sistemas de tecnologia e infraestrutura de água e não em oposição a estes.

Neste cenário, percebe-se a importância de integração de gestores e população na criação de redes unidas pelo interesse não só de uma melhor gestão dos recursos hídricos, como também voltadas para o desenvolvimento sustentável da região. A gestão das águas para o semiárido deve ser pautada por políticas públicas permanentes e apropriadas para diferentes realidades sociais, ampliando a capacidade humana local e quebrando com as estruturas de concentração da terra, da água, do poder e do acesso a serviços sociais básicos.

\section{REFERÊNCIAS}

ABERS, R.N; KECK, M.E.; Practical Authority: Agency and Institutional Change in Brazilian Water Politics. Published to Oxford Scholarship Online: September 2013. Disponível

em: <http://dx.doi.org/10.1093/acprof:oso/9780199985265.001.0001>. doi: 10.1093/acprof:oso/9780199985265.001.0001

ASSAD, L.T.; ALDEANUEVA, C.M.; CURI, M.; LITRE, G.; Do combate à seca à convivência com o Semiárido - Novos caminhos à procura da sustentabilidade. Sustentabilidade em Debate - Brasília, v. 7, Edição Especial, p. 7-21, dez/2016. Disponível em: <http://dx.doi.org/ 10.18472/SustDeb.v7nEsp.2016.21522>.doi:10.18472/SustDeb.v7nEsp.2016.21522.

AZEVEDO, L.G.T.; PORTO, R.L.L.; MÉLLO JUNIOR, A.V.; PEREIRA, J.G.; ARROBAS, D.L.P.; NORONHA, L.C.P.; Transferência de Água entre Bacias Hidrográficas. Banco Mundial, 1를 Edição, 1를 Reimpressão, 93 p., Brasília, 2005.

BARBOSA, E.M.; BARBOSA, M.F.N.; Direito de Águas Doces do Brasil: Uma Reflexão Epistemológica e Hermenêutica. Revista NEJ - Eletrônica, v. 18 - n. 2 - p. 240-255 / mai/ago 2013. Disponível em: <http://dx.doi.org/10.14210/nej.v18n2.p240- 
255>. doi: 10.14210/nej.v18n2.p240-255

BISWAS, A.k.; History of hidrology. North-Holland Publishing Co., Amsterdam, 1970. Disponível em: <http://dx.doi.org/ 10.1002/qj.49709741120>. doi: 10.1002/qj.49709741120

CASTRO, C.N.;Transposição do Rio São Francisco: Análise de Oportunidade do Projeto. IPEA - Instituto de Pesquisa Econômica Aplicada, textos para discussão. Rio de Janeiro, fev. de 2011.

CAÚLA, B.Q.; MOURA G.B. Aspectos Ambientais e Jurídicos da Transposição do Rio São Francisco. UNIFOR-CE, Maio, 2006.

CHAMUSCA, P. Novos desafios e objetivos de governação territorial: discutindo a reorganização do Estado e a conceptualização da governança como modelo de gestão dos territórios. GOT - Revista de Geografia e Ordenamento do Território, 2013, no 4. Disponível em: <http://dx.doi.org/ 10.17127/got/2013.4.002>. doi: $10.17127 / g o t / 2013.4 .002$

CIRILO, J. A. Políticas públicas de recursos hídricos para o semiárido. Estudos Avançados, São Paulo, v. 22, p. 63, 2008.

DOMINGUES, R.; Ordenamento territorial, governança e a transposição de águas do São Francisco: uma perspectiva. Revista de Geografia e Ordenamento do Território, 2015, n. 8. Disponível em: <http://dx.doi.org/ 10.17127/got/2015.8.004>. doi: $10.17127 / \mathrm{got} / 2015.8 .004$

FERNANDES, M.B.; O critical legal studies como forma de explicar a injustiça ambiental. Revista Brasileira de Sociologia do Direito, Julho de 2014. Disponível em: <http://dx.doi.org/ 10.21910/rbsd.v1n1.2014.40>. doi: $10.21910 /$ rbsd.v1n1.2014.40

FRACALANZA, A.P.; JACOB, A.M.; EÇA, R.F.; Justiça ambiental e práticas de governança da água: (re)introduzindo questões de igualdade na agenda. In.: Ambiente e sociedade, São Paulo, v. XVI, n. 1, jan.-mar./2013. p. 19-38. Disponível em: <http://dx.doi.org/10.1590/s1414-753x2013000100003>. doi: $10.1590 / \mathrm{s} 1414-753 \times 2013000100003$

GOMES, G. M. Velhas secas em novos sertões. Brasília: Ipea, 2001. 326p.

HENKES, S.L.;A política, o direito e o desenvolvimento: Um estudo sobre a transposição do rio São Francisco. Revista Direito GV, São Paulo 10(2) | P. 497534 | Jul-Dez 2014. Disponível em: <http://dx.doi.org/ 10.1590/1808-243220142>. doi: 10.1590/1808-2432201421

HOLZMANN, A.; Cooperação descentralizada como instrumento da governança global na gestão do meio ambiente. Revista Vernáculo, № 33, 1o sem./2014. Disponível em: <http://dx.doi.org/ 10.5380/rv.v0i33.37165>. doi: 10.5380/rv.v0i33.37165 
JACKSON, T. Prosperidade sem crescimento: vida boa em um planeta finito. São Paulo: Planeta Sustentável; Ed. Abril, 2013.

JACOBI, P.R.; SINISGALLI, P.A.A.; Governança ambiental e economia verde. Ciência \& Saúde Coletiva, v.17, n.6, Rio de Janeiro, Jun. 2012. Disponível em: <http://dx.doi.org/10.1590/S1413-81232012000600011. doi: 10.1590/S141381232012000600011.

DERANI, C.; JODAS, N.; Pagamento por serviços ambientais (PSA) e a racionalidade ambiental: aproximações. SCientia luris, Londrina, v.19, n.1, p.9-27, jun.2015. Disponível em: <http://dx.doi.org/ 10.5433/2178-8189.2015v19n1p9>. doi: 10.5433/2178-8189.2015v19n1p9

MANCAL, A.; LIMA, P.V.P.S; KHAN, A.S.; MAYORGA, M.I.O.; À espera da seca que vem: capacidade adaptativa em comunidades rurais do semiárido. Revista Brasileira de Estudos da População, Rio de Janeiro, v.33, n.2, p.257-281, maio/ago. 2016. Disponível em: <http://dx.doi.org/10.20947/s0102-30982016a0012>. doi: $10.20947 / \mathrm{s} 0102-30982016 a 0012$

MEDEIROS, S.S.; GHEYI, H.R. GALVÃO, C.O.; PAZ, V.P.S.; Recursos hídricos em regiões áridas e semiáridas. Instituto Nacional do Semiárido, Campina GrandePB, 2011.

NETO, F.V.A.; VIANNA, P.C.G.; Análise Espacial das Obras de Integração do Rio São Francisco - PISF (Eixo Leste) no estado da Paraíba. Geo UERJ, Rio de Janeiro, n. 28, p. 219-241, 2016. Disponível em: <http://dx.doi.org/10.12957/geouerj.2016.14536>. doi: 10.12957/geouerj.2016.14536.

OLIVEIRA, M.V.P.; ARAÚJO, R.N.; RODRIGUES, L.C.; SAMPAIO, J.L.F.; Sertão/Açudes no Imaginário Social e as Políticas de Desenvolvimento Recente no Nordeste. Revista Faculdade santo agostinho, Teresina, v.14, n.1, art. 6, p. 129148, jan./fev. 2017. Disponível em: <http://dx.doi.org/10.12819/2017.14.1.6>. doi: 10.12819/2017.14.1.6

PBMC. Sumário Executivo do Volume 1 - Base Científica das Mudanças Climáticas. Contribuição do Grupo de Trabalho 1 para o 10 Relatório de Avaliação Nacional do Painel Brasileiro de Mudanças Climáticas. Brasil, Volume Especial para a Rio+20, 2012, 34p.

QUOSY, D. E.D. E. Agricultural development in Egypt across two millenniums. Virtual Global Super Project Conference, 2001. (World Development Federation). [on line]. <www.wdf.org/gspc>. 2005.

RIMA. Relatório de Impacto Ambiental. Projeto de integração do Rio São Francisco com Bacias Hidrográficas do Nordeste Setentrional. Ministério da Integração Nacional. Brasília, Julho de 2004.

SEN, A. Desenvolvimento como liberdade. Companhia das Letras, 2008. 
SHRE. Snowy Mountains Scheme. [on line]. <www.snowyhydro.com.au>. 27. out. 2004. Acesso em: 22 de maio de 2015.

SILVA, J.I.A.O. Ecologização de megaprojetos hídricos: o caso da transposição do Rio São Francisco. Agua y Territorio, n.4, p. 59-69, Universidad de Jaén, Jaén, España, Julio-Diciembre 2014. Disponível: <http://dx.doi.org/10.17561/at.v1i4.2164>. doi: $10.17561 /$ at.v1i4.2164.

SILVEIRA,C. S., SOUZA FILHO, F. A. , LOPES, J. E. G., BARBOSA, P. S. F., TIEZZI, R. O. Análise das projeções de vazões nas bacias do setor elétrico brasileiro usando dados do IPCC-AR4 para o século XXI. Revista Brasileira de Recursos Hídricos, v. 19,n. 4, p. 59-71, 2014. Disponível em: <http://dx.doi.org/10.21168/rbrh.v19n4.p59-71>. doi: 10.21168/rbrh.v19n4.p59-71

TORRES, Roberto Dutra. Governabilidade, governança e poder informal. Civitas, Porto Alegre, v. 16, n. 1, p. 153-171, jan.-mar. 2016. Disponível em: <http://dx.doi.org/10.15448/1984-7289.2016.1.19581>. doi:10.15448/19847289.2016.1.19581

WWF (2007). Pipedreams Interbasin Water Transfers and Water Shortages. Disponível em: https://www.wwf.or.jp. Acesso em: 12 de maio de 2015. 
